\title{
Src Inhibits Midline Axon Crossing Independent of Frazzled/ Deleted in Colorectal Carcinoma (DCC) Receptor Tyrosine Phosphorylation
}

\author{
Michael P. O’Donnell ${ }^{1,2}$ and Greg J. Bashaw ${ }^{2}$ \\ ${ }^{1}$ Cell and Molecular Biology Graduate Group and ${ }^{2}$ Department of Neuroscience, University of Pennsylvania School of Medicine, Philadelphia, Pennsylvania \\ 19104
}

The phylogenetically conserved Netrin family of chemoattractants signal outgrowth and attractive turning of commissural axons through the Deleted in Colorectal Carcinoma (DCC) family of receptors. Src family kinases are thought to be major signaling effectors of Netrin/ DCC. In vertebrates, Src and the closely related Fyn kinases phosphorylate DCC and form a receptor-bound signaling complex leading to activation of downstream effectors. Here we show that, in the Drosophila embryonic CNS, Src kinases are dispensable for midline attraction of commissural axons. Consistent with this observation, tyrosine phosphorylation of the Netrin receptor DCC or its Drosophila ortholog, Frazzled, is not necessary for attraction to Netrin. Moreover, we uncover an unexpected function of Src kinases: inhibition of midline axon crossing through a novel mechanism. We propose that distinct signaling outputs must exist for midline axon crossing independent of Src kinases in commissural neurons.

\section{Introduction}

Bilaterally symmetric animals must coordinate left and right sensorimotor information. Contralateral connectivity is in part achieved during embryogenesis when commissural neurons project axons across the midline, a source of instructive cues. In bilaterians, midline-derived Netrin and its neuronal receptor Deleted in Colorectal Carcinoma (DCC) promote commissural axon crossing (Evans and Bashaw, 2010). Embryos lacking Netrins or DCC have profound commissural axon defects in all animals studied, though much of the mechanism of Netrin-DCC signal transduction has been revealed through in vitro approaches (Round and Stein, 2007). DCC family members have no known catalytic motifs, and axon attraction to Netrin through DCC is thought to involve a combination of locally induced changes in second messengers as well as activation of intracellular kinasedependent signaling cascades (Lai Wing Sun et al., 2011).

One output of Netrin signaling is the regulation of the Rho family GTPases, Rac and Cdc42 (Li et al., 2002; Shekarabi and Kennedy, 2002; Gitai et al., 2003; Shekarabi et al., 2005). Though the precise mechanism of Rac regulation is not known, it has been proposed that tyrosine phosphorylation of DCC by Src family

\footnotetext{
Received June 8, 2012; revised 0ct. 10, 2012; accepted Nov. 5, 2012.

Author contributions: M.O. and G.J.B. designed research; M.0. performed research; M.0. contributed unpublished reagents/analytic tools; M.0. analyzed data; M.O. and G.J.B. wrote the paper.

This work was supported by National Institutes of Health Grants NS-046333and NS054739 (G.J.B.), March of Dimes Foundation Research Grant 1-FY12-445, and NIH Training Grants 5-T32-GM07229 and 5-T32-007516 (M.0.). We are grateful to members of the Bashaw lab for helpful comments on this manuscript. We thank Nathalie Lamarche-Vane, Alana $0^{\prime}$ Reilly, and Amin Ghabrial for reagents.

The authors declare no competing financial interests.

Correspondence should be addressed to Greg J. Bashaw at the above address. E-mail: gbashaw@mail.med.upenn.edu.

DOI:10.1523/JNEUROSCI.2756-12.2013

Copyright $\odot 2013$ the authors $\quad 0270-6474 / 13 / 330305-10 \$ 15.00 / 0$
}

kinases (SFKs) results in the formation of a signaling complex that activates Rac (Meriane et al., 2004). Consistent with this model, Netrin stimulation recruits SFKs to the DCC receptor cytoplasmic domain through focal adhesion kinase (FAK) (Li et al., 2004; Liu et al., 2004; Ren et al., 2004). Pharmacological inhibition or genetic disruption of SFK activity blocks Netrindependent responses in cultured neurons (Li et al., 2004; Liu et al., 2004; Meriane et al., 2004). Moreover, a DCC receptor bearing a mutation of the Fyn/Src target tyrosine (Y1420F) acts as a dominant negative when expressed in cultured Xenopus spinal neurons (Li et al., 2004). These data suggest that the phenotype of Src loss-of-function mutants should mimic the loss of Netrin or DCC. Knock-out (KO) embryos deficient for the two SFKs implicated in these studies (Fyn and Src) develop relatively normally with few overt phenotypic defects. However, commissural axon pathfinding in these mice has not been closely analyzed (Soriano et al., 1991; Stein et al., 1992). Also, given the large Src gene family in vertebrates, other SFKs might compensate for the loss of Src and Fyn in these animals, as they do in other processes (Stein et al., 1994).

In Drosophila, only two genes encode SFKs: $\operatorname{Src} 42 \mathrm{~A}$ and Src64B. Therefore, we reasoned that the Drosophila embryonic CNS could be a simpler system to understand the in vivo contribution of SFKs to Netrin signaling. Embryonic commissural neurons require both Netrin (encoded by NetA and NetB genes) and the fly ortholog of DCC, Frazzled (Fra), for midline axon crossing (Kolodziej et al., 1996; Mitchell et al., 1996). We find here that, in contrast to the proposed function of SFKs as effectors of Netrin signaling, Src kinases antagonize midline axon crossing in Drosophila through a novel pathway. Additionally, we show that tyrosine phosphorylation of DCC receptors is dispensable for their roles in commissural and motor axon guidance. We therefore 
posit the existence of a novel Netrin-DCC signaling output that is Src independent.

\section{Materials and Methods}

Molecular biology. For Fra-Myc and DCC-Myc, all generated transgenic constructs were cloned into a pUAST vector containing $10 \times$ UAS and an attB site for PhiC31-mediated targeted insertion (p10UAST-attB). All were cloned along with a C-terminal $6 \times$ Myc epitope. Fra-Myc was cloned as an EcoR1/Not1 fragment from pUAST-Fra-Myc (Garbe and Bashaw, 2007). Rat DCC and DCCY1418F were cloned from pRK5-DCC (Li et al., 2002) and pRK5-DCCY1418F (Meriane et al., 2004) in two steps into p10UAST-attB using an EcoR1/Xbal fragment followed by an EcoR1/EcoR1 fragment. Fra-9YF was generated by stepwise PCR mutagenesis of individual or multiple sites in close proximity. Mutated tyrosine residues are Y1113, Y1170, Y1189, Y1193, Y1207, Y1212, Y1247, Y1250, and Y1313. All constructs were fully sequenced. Transgenic flies were generated by Best Gene.

Genetics. The following alleles were used in this study: for frazzled, fra ${ }^{3}$, $\mathrm{fra}^{4}, \mathrm{Df}(2 \mathrm{R}) \operatorname{vg} 135$ (Kolodziej et al., 1996), and $\mathrm{fra}^{6}$ (Yang et al., 2009); for Netrin, NetABD (Brankatschk and Dickson, 2006); for Src42A, Src42A ${ }^{E 1}$ (Tateno et al., 2000), Src42A $A^{k 10108}$ (Lu and Li, 1999); for Src64BB, $\operatorname{Src64B^{KO}}$ (O'Reilly et al., 2006); for derailed, $d r l^{R 343}$ (Callahan et al., 1995); for Unc-5, Unc- $5^{2}$ (Labrador et al., 2005); for myospheroid, mys $^{1}$ (Wright, 1960); for roundabout, robo ${ }^{1}$ (Kidd et al., 1998); for eagle, $e^{\mathrm{MZ360}}\left(\mathrm{eg}-\mathrm{Gal}\right.$ ) (Dittrich et al., 1997); and for apterous, ap ${ }^{\text {Gal4 }}$ (Benveniste et al., 1998). The following transgenes were used: (1) $P\{U A S-F r a-$ $M y c\} 86 F b$, (2) P $\{U A S-F r a-9 Y F-M y c\} 86 F b$, (3) P $\{U A S-D C C-M y c\} 86 F b$, (4) $P\{U A S-D C C Y 1418 F-M y c\} 86 F b$, (5) P $\{U A S-F r a \Delta C-H A\} \# 4$ (Garbe et al., 2007), (6) P\{UAS-TauMycGFP $\}$ II, (7) P\{UAS-TauMycGFP $\}$ III, (8) constitutively active $\operatorname{Src64B}, P\left\{U A S-S r c 64^{Y 547 F}\right\}$ III, Src64 (O'Reilly et al., 2006), and (9) P\{GAL4-elav.L\}3. All crosses were performed at $25^{\circ} \mathrm{C}$. Embryos were genotyped using a combination of marked balancer chromosomes, the presence of linked transgenes, or, in the case of NetABD mutants, the absence of fluorescent mRNA in situ hybridization signal. Where possible, all comparative phenotypes were analyzed in the same genetic background to limit the effects of potential modifier mutations. Exceptions to this are listed here. For Figure $3 E$ (left) as well as Figure $2 D$ (right), "fra hypo" depicts the genotype $f \mathrm{ra}^{3}$, [UAS-TauMycGFP]/fra ${ }^{6}$;eg$\mathrm{Gal} 4 /+$, whereas in Figure $3 E$ (middle left), "fra hypo" depicts the genotype $\mathrm{fra}^{3} / \mathrm{fra}^{6} ; e \mathrm{~g}-\mathrm{Gal} 4$, [UAS-TauMycGFP]/+. For Src64 genetic suppression experiments, the $S r c 64^{K O}$ allele was used in trans to eg-Gal4 in Figure $2 D$ (right), whereas in Figure $3 E$ a recombinant $\operatorname{Src6} 4^{K O}$, eg-Gal4 chromosome was used.

Immunostaining/imaging. Dechorionated, formaldehyde-fixed, methanoldevitellinized embryos were fluorescently stained using standard methods. The following antibodies were used in this study: mouse mAb BP102 (1:100), mouse anti-Fasciclin-II/mAb 1D4 (1:100), rabbit anti-GFP (Invitrogen, catalog \#A11122; 1:500), rabbit anti-c-Myc (Sigma C3956; 1:500), Alexa 647-conjugated goat-anti-HRP (Jackson ImmunoResearch, catalog \#123-605-021; 1:250), Cyanine 3-conjugated goat antimouse (Jackson ImmunoResearch, catalog \#115-165-003; 1:1000), and Alexa 488-conjugated goat anti-rabbit (Invitrogen, catalog \#A11008; 1:500). Embryos were mounted in 70\% glycerol/PBS. Fluorescent mRNA in situ hybridization was performed as described previously (Garbe and Bashaw, 2007). Phenotypes were analyzed, and images were acquired using a spinning disk confocal system (PerkinElmer) built on a Nikon Ti-U inverted microscope using a Nikon OFN25 $60 \times$ objective with a Hamamatsu C10600-10B CCD camera and Yokogawa CSU-10 scanner head with Volocity imaging software. Images were processed using ImageJ.

Phenotypic quantification. For EW commissural neuron crossing phenotypes, whole-mount embryos were analyzed at Stages 15 and 16. Eight abdominal segments were analyzed per embryo where possible, and for each embryo, the percentage of noncrossing segments was calculated. A segment was considered noncrossing when both clusters of EW axons (six axons per segment) failed to make an orthogonal turn toward the midline. SEM as depicted in figures was based on the number of embryos per genotype. For apterous ectopic crossing phenotypes, whole-mount embryos were analyzed at Stage 17. Eight abdominal segments were scored per embryo. When a segment contained a continuous crossing projection of at least the thickness of incoming axons from ap cell bodies, it was considered an ectopic cross. For muscle 6/7 innervation defects, Stage 17 embryos were filleted. Ten abdominal hemisegments were analyzed per embryo. An innervation was considered absent when no projection of FasII-positive axons could be detected originating from the intersegmental nerve $\mathrm{b}$ in the muscle $6 / 7$ cleft. Only segments where muscles and nerve had not been disrupted in the dissection process were analyzed. Muscles were identified using DIC optics. For quantification of phenotypes using $\mathrm{mAb} \mathrm{BP} 102$, posterior commissures were scored as defective if they were absent or substantially thinner than in wild-type (WT) embryos. For statistical analysis of guidance phenotypes, comparisons were made using generalized estimate equations for clustered binary data, using $\mathrm{R}$ software. Correlation structure was chosen based on calculation of quasi-log-likelihood under the independence model information criterion and correlation information criterion as described previously (Pan, 2001; Hin and Wang 2009). For multiple comparisons, a post hoc Bonferroni correction was applied. The $p$ values are based on corresponding Wald statistics.

\section{Results}

Drosophila Src mutants are not deficient in midline axon attraction, but resemble integrin loss-of-function mutants

Based on the model of receptor-associated kinase signaling in vertebrates (Li et al., 2004; Liu et al., 2004; Meriane et al., 2004; Ren et al., 2004), we expected that Src mutants in Drosophila would have defects in midline axon attraction, similar to Netrin and fra mutants. Netrin and Fra are required primarily for the formation of axonal commissures of the embryonic CNS. We were surprised, however, to see that CNS axons appeared to cross relatively normally in embryos lacking both of the two Drosophila $\operatorname{Src}$ genes, $\operatorname{Src42A}$ and $\operatorname{Src64B}$ (Wouda et al., 2008). We therefore decided to examine $\operatorname{Src}$ mutants more closely to determine whether these embryos have subtle axon crossing defects. Using an antibody to label all axons in single and double Src mutants, we found that most commissural axons appear to cross appropriately, although there are defects in the separation of the anterior and posterior commissures in double mutants, as reported previously (Fig. 1G) (Wouda et al., 2008). To evaluate commissural axon guidance more quantitatively, we labeled the eagle-positive subset of commissural neurons (EW neurons) using eg-Gal4 to drive expression of an axon marker, Tau-Myc-GFP. However, we found no defects in EW midline axon crossing, even in $\operatorname{Src42A}$; Src64B double mutants (Fig. $1 J-N$; Table 1).

In contrast to the relatively normal CNS in single Src mutants, in $\operatorname{Src42A}$; $\operatorname{Src64B}$ double mutants there are severe defects in FasII-positive ipsilateral axons, which often cross the midline inappropriately (Fig. $1 G$ ). These axons depend on repulsive SlitRobo signaling for pathfinding (Seeger et al., 1993; Kidd et al., 1998), but often cross in embryos in which adhesion has been reduced as well, as seen in integrin loss-of-function mutants (Loureiro and Peifer, 1998; Speicher et al., 1998; Stevens and Jacobs, 2002). Accompanying these CNS malformations are profound patterning defects including partial head involution, defective dorsal closure, and a failure of germ-band retraction, as reported previously ( $\mathrm{Lu}$ and Li, 1999; Takahashi et al., 2005). Because we observe these patterning defects, and because midline and lateral glia are frequently mispositioned in these mutants (Wouda et al., 2008) (data not shown), it is difficult to conclusively interpret the CNS phenotype in these embryos.

\section{Src antagonizes midline axon crossing through an integrin-independent pathway}

The pleiotropic defects in Src double mutants confound the interpretation of the midline crossing phenotype of EW neurons. It 

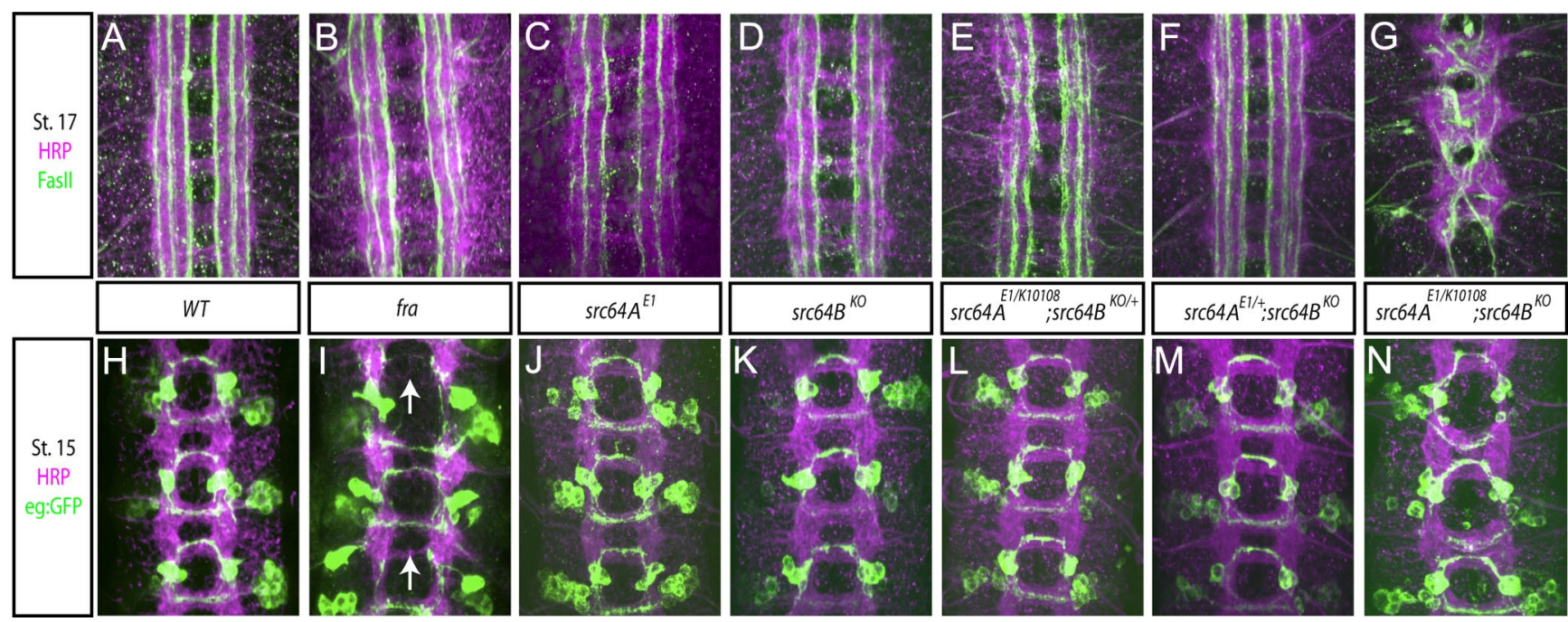

Figure 1. Commissural axon pathfinding is normal in Src mutant embryos. $\boldsymbol{A}-\boldsymbol{N}$, Representative Stage $17(\boldsymbol{A}-\boldsymbol{G})$ and Stage $15(\boldsymbol{H}-\boldsymbol{N})$ embryos of indicated genotypes stained using anti-HRP (magenta) to label all axons, in addition to anti-Fasll $(\boldsymbol{A}-\boldsymbol{G}$, green) and anti-GFP $(\boldsymbol{H}-\boldsymbol{N}$, green) to label ipsilateral and eg-positive commissural neurons, respectively. Anterior is up. $\boldsymbol{A}, \boldsymbol{H}$, Wild-type embryos. Three ipsilateral Fasll-positive axon pathways have formed properly $(\boldsymbol{A})$, eg-positive commissural axons have all properly crossed the midline at this stage $(\boldsymbol{H}) . \boldsymbol{B}, \boldsymbol{I}$, fra ${ }^{3} / \mathrm{fra}^{4}$ mutants. Fasll-positive axons remain ipsilateral but occasional breaks in longitudinal pathways occur $(\boldsymbol{B})$. eg-positive commissural axons frequently mistarget ipsilaterally $(\boldsymbol{I}$, arrows). $\mathbf{C}-\boldsymbol{F}, \boldsymbol{J}-\boldsymbol{M}, \operatorname{Src}$ mutant embryos. Fasll-positive axons display occasional wandering/defasciculation but remain ipsilateral (C-F). EW neurons project axons normally (J-M). G, N, Src42A;Src64B double mutants. Severe defects in Fasll-positive axons including stalling and midline collapse ( $\boldsymbol{G}$ ). EW axons cross normally in Src double mutants despite substantial patterning defects $(\boldsymbol{N})$. For quantification of the EW crossing phenotype, see Table 1.

Table 1. Quantification of EW crossing defects in src and fra mutants, including transgenic rescue

\begin{tabular}{|c|c|c|c|c|c|}
\hline Genotype & Noncrossing (\%) & SEM (\%) & $n$ (segments) & $n$ (embryos) & $p$ \\
\hline \multicolumn{6}{|l|}{ srcmutants } \\
\hline $\mathrm{fra}^{3},[$ UAS-TauMycGFP $] / \mathrm{fra}^{3} ;[\mathrm{eg}-\mathrm{Gal} 4] \mathrm{J}+$ & 20.15 & 4.06 & 168 & 21 & \\
\hline Src42a $a^{E 1} / S r c 42 a^{E 1},[$ UAS-TauMycGFP $] ;[$ eg-Gal4] $/+$ & 0.63 & 0.63 & 160 & 20 & \\
\hline Src42a $a^{E 1},[$ UAS-TauMycGFP $] / ; \operatorname{Src64b} b^{K O},[\mathrm{eg}-\mathrm{Gal} 4] / \mathrm{Src} 64 b^{K O}$ & 0 & 0 & 120 & 15 & \\
\hline Src42a $a^{E 1},\left[\right.$ UAS-TauMycGFP]/Src42a $a^{k 10108} ;$ Src64b ${ }^{K O},\left[\right.$ eg-Gal4] $/ S r c 64 b^{K O}$ & 0.89 & 0.89 & 110 & 14 & \\
\hline $\mathrm{fra}^{3},\left[\right.$ UAS-TauMycGFP]/Src42a $a^{k 10108} ; \operatorname{Src} 64 b^{K 0} /[\mathrm{eg}-\mathrm{Gal} 4]$ & 0 & 0 & 88 & 11 & \\
\hline \multicolumn{6}{|l|}{ fra rescue in EW neurons } \\
\hline $\mathrm{fra}^{3},[$ UAS-TauMycGFP $] / f r a^{4} ;[\mathrm{eg}-$ Gal4] $/+$ & 25.78 & 3.93 & 183 & 23 & \\
\hline $\mathrm{fra}^{3},[$ UAS-TauMycGFP $] / \mathrm{fra}^{4} ;[$ eg-Gal4] [UAS-FraWT-Myc $]$ & 11.88 & 3.20 & 160 & 20 & 0.027 \\
\hline $\mathrm{fra}^{3},[$ UAS-TauMycGFP]/fra $;$; [eg-Gal4][UAS-DCCWT-Myc] & 3.75 & 1.60 & 160 & 20 & $<0.0001$ \\
\hline $\mathrm{fra}^{3},\left[\right.$ UAS-TauMycGFP]/fra ${ }^{4} ;[\mathrm{eg}-$ Gal4] [UAS-DCCY1418F-Myc] & 6.34 & 2.95 & 159 & 20 & 0.009 \\
\hline $\mathrm{fra}^{3},\left[\right.$ UAS-TauMycGFP]/fra ${ }^{4} ;[$ eg-Gal4] [UUS-FragYF-Myc] & 5.56 & 2.20 & 72 & 9 & $<0.0001$ \\
\hline $\mathrm{fra}^{3},[$ UAS-TauMycGFP]/Df(2R)vg135; [eg-Gal4]/+ & 27.08 & 3.72 & 96 & 12 & \\
\hline $\mathrm{fra}^{3}$,[UAS-TauMycGFP]/Df(2R)vg 135;[eg-Gal4][UAS-FraWT-Myc] & 5.09 & 1.80 & 216 & 27 & $<0.0001$ \\
\hline $\mathrm{fra}^{3}$,[UAS-TauMycGFP]/Df(2R)vg135; [eg-Gal4][UAS-DCCWT-Myc] & 2.50 & 1.15 & 160 & 20 & $<0.0001$ \\
\hline $\mathrm{fra}^{3},[$ UAS-TauMycGFP]/Df(2R)vg135; [eg-Gal4][UUAS-DCCY1418F-Myc] & 5.15 & 2.16 & 136 & 17 & 0.00014 \\
\hline $\mathrm{fra}^{3},[$ UAS-TauMycGFP]/Df(2R)vg135; [eg-Gal4]/UAS-FragYF-Myc] & 4.17 & 1.57 & 168 & 21 & $<0.0001$ \\
\hline
\end{tabular}

Stage 15 and 16 embryos were whole mounted and scored for the EW noncrossing phenotype (see Materials and Methods). For rescue experiments, $p$ values for each subgroup are relative to the control fra mutant phenotype (listed first).

is possible, though unlikely, that SFKs play an essential role in midline axon crossing that is masked in this genetic background due to a requirement for $S r c$ function in an independent process. In principle, this function should be revealed in sensitized genetic backgrounds. If Src function is essential in Netrin-dependent attraction, this should be evident when Netrin signaling is partially reduced. We observed no effect on the guidance of EW neurons in embryos that are compound heterozygous mutant for fra and either $\operatorname{Src42A}$ or $\operatorname{Src64B}$ (data not shown). To further reduce Netrin signaling, we analyzed embryos expressing a truncated Frazzled receptor, Fra $\Delta \mathrm{C}$ (DN-Fra), in EW neurons (Fig. 2B). We showed previously that this receptor acts as a dominant negative for Fra (Garbe et al., 2007). Surprisingly, instead of exacerbating the fra loss-of-function phenotype, Src mutations actually suppress the midline crossing defects caused by DN-Fra expression (Fig. 2D). We observed suppression of midline crossing defects in both $S r c 42 A$ and $S r c 64 B$ mutants, and these effects are dependent on the amount of endogenous $S r c$ gene dose. This suppression is not due to a reduction in DN-Fra transgene expression levels, as immunostaining for an epitope tag (HA) on this transgene appears identical in embryos that are wild-type and mutant for SFKs (Fig. 2E-J). The suppression of midline crossing defects in Src mutants is both potent and specific; we observed almost a full rescue of midline crossing in embryos in which three of four gene copies of $S r c$ are mutant, and this effect can be seen independent of any obvious patterning defects. Src mutations also suppress midline axon crossing defects in fra hypomorphic allelic combinations (Figs. 2D, $3 A, B, E$ ), suggesting that SFKs can antagonize endogenous Fra function in commissural neurons. Additionally, when we analyzed commissural guidance using mAb BP102 to label all axons, we observe a substantial reduction in defects in these embryos, similar to our observations in EW neurons ( $45 \pm$ 

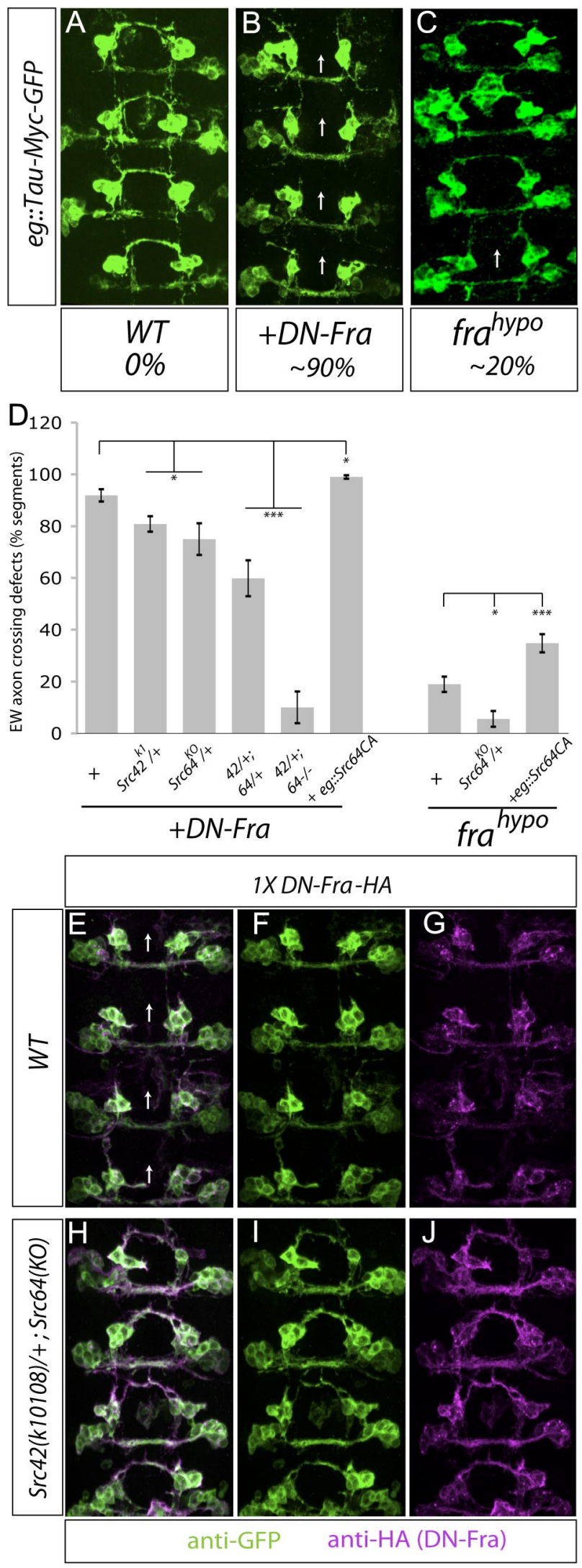

Figure 2. Src42A and Src64B antagonize midline axon crossing. $A-D$, EW midline crossing defects were scored at Stages 15 and 16 using eg-Gal4 to express TauMycGFP, after immunostaining for anti-GFP. $A$, Wild-type embryo. $\boldsymbol{B}$, An embryo expressing DN-Fra in, e.g., neurons. Most EW axons misproject (arrows). C, An fra ${ }^{3} / f r a^{6}$ hypomorphic mutant. EW axons fail to cross in $\sim 20 \%$ of segments (arrow). D, quantification of EW crossing defects in DN-Fra (left) and fra ${ }^{h y p o}$ (right) backgrounds. Reduction in Src gene dose rescues midline crossing defects, while increasing Src activity in EW neurons increases phenotypic severity. Error bars indicate
$4.2 \%$ defects, $n=20$ in $\mathrm{fra}^{3} / \mathrm{fra}^{6}$ vs $19.8 \pm$ $3.2 \%$ defects, $n=21$ in $\mathrm{fra}^{3} / \mathrm{fra}^{6}$; $\left.\mathrm{Src6}^{K O} /+; p<0.0001\right)$. This suggests that Src inhibits midline crossing in many other commissural neurons in addition to EW neurons. To determine whether Src acts autonomously in commissural neurons to inhibit midline crossing, we expressed a constitutively active $\operatorname{Src64B}$ (Src64CA) in EW neurons. While expression of Src64CA has no effect in wild-type embryos (data not shown), expression in backgrounds with reduced Netrin-Fra signaling exacerbates midline crossing defects (Fig. 2D), suggesting that Src exerts its effect on midline crossing cell autonomously.

The observed genetic suppression of multiple fra loss of function phenotypes is consistent with Src functioning to antagonize Netrin signaling, but also could reflect a role for Src in a parallel pathway regulating midline axon crossing. If Src acts exclusively in the Netrin pathway, we would not expect to see similar suppression of midline crossing defects when Srcmutationsareintroduced into Netrinnull mutants. However, the NetA, NetB double mutant phenotype is also suppressed in $\operatorname{Src} 64 B$ heterozygotes (Fig. $3 C-E$ ), suggesting that Src acts via a Netrin-independent pathway in these neurons in addition to any role it may play in inhibiting Netrin-Frazzled signaling. Because Src functions as an effector of Netrin-Unc-5 repulsive axon guidance, we tested whether Unc-5 signaling is active in these neurons (Itoh et al., 2005).

$\leftarrow$

SEM. $p$ values are calculated from Wald statistics, relative to the control background, DN-Fra (left), and fra ${ }^{\text {hypo }}$ (right). ${ }^{*} p<0.05$; ${ }^{* * *} p<0.001$. See Materials and Methods for details on statistical analysis. $E-J, D N-$ Fra expression is not reduced in Srcmutants. Embryos expressing TauMycGFP ( $\boldsymbol{F}, \boldsymbol{I}$, anti-GFP, green) and DN-Fra ( $\boldsymbol{G}$, $J$, anti-HA, magenta) in EW neurons exhibit severe crossing defects ( $\boldsymbol{E}$, arrows) in wild-type embryos $(\boldsymbol{E}-\boldsymbol{G})$ that are almost fully rescued in Src42A/+;Src64-/- mutants (H-J). Specific genotypes are as follows: $\boldsymbol{A}$, "wt": [eg-Gal4],[UAS-TauMycGFP]/+; $\boldsymbol{B}$, "DNFra": [UAS- FraC-HA] 4,[UAS-TauMycGFP]/+; [eg-Gal4/+; C, "fra hypo": fra $^{3}$, [UAS-TauMycGFP]/fra ${ }^{6}$; [eg-Gal4]/+; D, left, "+" [UAS-FraC-HA] 4, [UAS-TauMycGFP]/+;eg-Gal4/+, "Src42/+": [UAS-DN-Fra] 4, [UAS-TauMycGFP]/Src42 ${ }^{\text {k10108; }}$ eg-Gal4/+, "Src64/+": [UAS-DN-Fra] 4, [UAS-TauMycGFP]/+; Src64 ${ }^{\mathrm{KO}} /+$, "42/+;64/+": [UAS-DN-Fra] 4, [UAS-TauMycGFP]/Src42 ${ }^{\text {k10108. }}$ eg-Gal4/Src64 "Ko "42/+;64-/-": [UAS-DN-Fra] 4, [UAS-TauMycGFP]/Src42 ${ }^{k: 10108} ; S_{16} 64^{K O}$, eg-Gal4/Src64 ${ }^{K O}$, right, " +": $\mathrm{fra}^{3}$,[UAS-TauMycGFP]/ fra ${ }^{6}$; [eg-Gal4]/+, "Src64/+": $\mathrm{fra}^{3}$, [UAS-TauMycGFP]/ fra ${ }^{6}$; [eg-Gal4]/Src64 ${ }^{\mathrm{KO}}$, "eg::Src64CA", $\mathrm{fra}^{3}$,[UAS-TauMycGFP]/fra ${ }^{6} ;[$ eg-Gal4]/[UAS-Src64-CA]; $E-G$, [UAS-Fra $\Delta$ C-HA]\#4,[UAS-TauMycGFP]/+;[eg-Gal4]/+; $\boldsymbol{H}-\boldsymbol{J}$, [UAS- $\quad F r a \Delta C-H A] \# 4,[U A S-T a u M y c G F P] / S r c 42 A^{k 10108}$; Src64B ${ }^{\mathrm{K} 0},[\mathrm{eg}-\mathrm{Ga} \mid 4] / \mathrm{Src} 64 \mathrm{~B}^{\mathrm{K} 0}$. See Materials and Methods for comments on genotypes. 

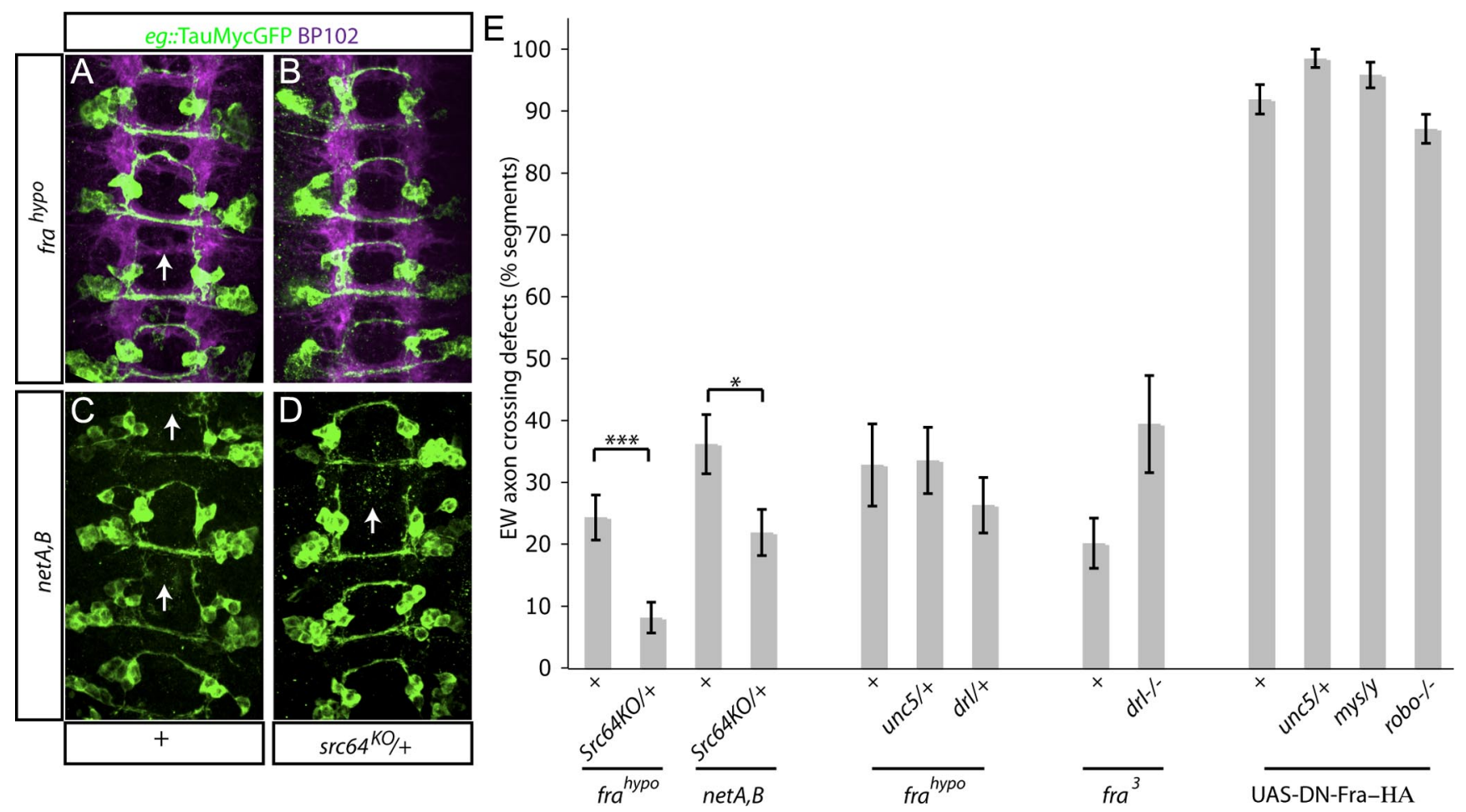

Figure 3. Inhibition of midline crossing by Src kinases occurs through a novel, Netrin-independent pathway that is not regulated through Derailed, Unc-5, or Integrin signaling. $\mathbf{A}-\mathbf{D}$, Representative Stage 15 embryos immunostained with anti-GFP to visualize EW axons ( $\boldsymbol{A}-\boldsymbol{D}$, green) and BP102 to visualize CNS axons ( $\boldsymbol{A}, \boldsymbol{B}$, magenta). $\boldsymbol{A}$, An fra ${ }^{\text {hypo }}$ embryo displays a partially penetrant EW crossing phenotype (arrow), which is suppressed in $\operatorname{Src6} 4^{K O}$ heterozygous mutants $(\boldsymbol{B}, \boldsymbol{E}) . \boldsymbol{C}-\boldsymbol{E}, \mathrm{ANet} A \boldsymbol{B}$-null mutant also displays partially penetrant EW axon defects (arrows), and these are similarly suppressed in Src $64^{K O}$ heterozygotes $(\boldsymbol{D}, \boldsymbol{E})$. E, Quantification of EW crossing defects in netrin and frazzled mutants bearing different candidate modifier mutations. Unlike Src64B, neither unc-5 nor

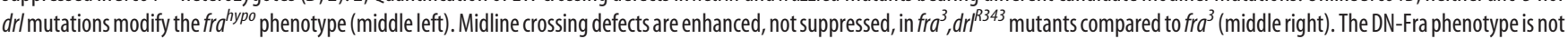
suppressed in unc- 5 heterozygotes, mys hemizyogotes, or robo homozygous mutants (right). Error bars indicate SEM. ${ }^{*} p<0.05$; ${ }^{* *} p<0.001$. See Materials and Methods for comments on genotypes.

While we detect Unc-5 mRNA expression in neuroblasts that give rise to EW neurons, this expression is eliminated in the EW neurons before axogenesis and is only maintained in their sibling, the GW motor neuron (data not shown). Moreover, Unc-5 mutations do not modify the fra loss-of-function phenotype in EW neurons (Fig. 3E). Thus, Src likely inhibits midline axon crossing through a pathway independent of Unc-5 and Netrin.

To determine whether Src acts in parallel to Fra in commissural guidance, we tested whether Src mutations suppress EW crossing defects in fra-null mutants using the predicted null $\mathrm{fra}^{3}$ allele. We find that in contrast to fra hypomorphs, heterozygosity for $\operatorname{Src6} 4^{\mathrm{KO}}$ does not suppress crossing defects in $\mathrm{fra}^{3}$ mutants (data not shown), suggesting that Src might play a role in the noncanonical, Netrin-independent fra pathway (Yang et al., 2009).

The existence of an additional attractive or repulsive pathway promoting midline axon crossing in Drosophila has been postulated due to the partially penetrant defects in Netrin and fra mutants. SFKs can function in multiple signaling pathways involved in axon guidance in Drosophila, which might account for these genetic interactions in commissural neurons. For example, Src64B acts in the Wnt5-Derailed (Drl)/Ryk pathway to promote anterior commissure choice (Wouda et al., 2008). In addition, in multiple systems, SFKs play a central role in integrin signaling, an important pathway in Drosophila axon guidance (Hoang and Chiba, 1998; Stevens and Jacobs, 2002; Legate et al., 2009), which could in principle account for our observed genetic interactions. To test these possibilities, we introduced mutations in components of these pathways into sensitized genetic backgrounds and quantified the EW crossing phenotypes (Fig. 3E). Drl heterozygous or homozygous mutations do not suppress the fra loss-offunction phenotype in EW neurons. Similar results were obtained using mutations in the single Integrin PS gene in Drosophila, myospheroid. Midline crossing defects caused by DN-Fra expression are not suppressed in robo mutants, suggesting Src's effects on midline crossing are not exclusively through regulation of the Slit-Robo pathway. These results indicate that Src likely inhibits midline axon crossing through a novel Integrin- and Derailed/Ryk-independent signaling pathway.

\section{DCC receptor phosphorylation is dispensable for}

Netrin-dependent axon attraction in Drosophila

One mechanism by which Src has been proposed to mediate Netrin-signaling is through direct receptor phosphorylation, presumably leading to the assembly of a downstream signaling complex that causes Rac activation (Li et al., 2004; Meriane et al., 2004). This precise mechanism of Src-dependent Netrin signaling is unlikely to occur in Drosophila because the essential tyrosine residue implicated in these studies is not conserved in Fra; however, a similar process could occur centering on one or multiple alternative tyrosine residues. To directly address whether a similar mechanism occurs in Drosophila, we sought to rescue fra loss of function phenotypes using rat DCC or Fra receptors in which tyrosine residues were mutated to phenylalanines. We generated transgenic flies expressing DCC or Fra with C-terminal Myc tags under Gal4/UAS control. To eliminate position effects, all DCC and Fra constructs used in these studies were inserted at the same genomic location, and are expressed and localized comparably 
when driven by the pan-neural elav-Gal4 (see Fig. 5H,I). To first determine whether rat DCC can signal in response to Drosophila Netrin, we made use of a gain-offunction assay in an ipsilaterally projecting subset of neurons using apterous-Gal4 (apGal4). When either Fra or DCC is expressed in these neurons, their axons aberrantly cross the midline (Fig. 4A-D). Importantly, the DCC-dependent crossing defects in this background are suppressed in NetAB $\Delta$ mutants, suggesting that this receptor can signal in response to Drosophila Netrin (Fig. 4D). To determine whether DCC can functionally compensate for Fra in commissural neurons, we expressed DCC constructs in EW neurons in fra mutants. DCC rescues fra midline crossing defects in EW neurons to a similar degree as Drosophila Fra (Fig. $5 A-D, G$; Table 1). Based on experiments in Xenopus neurons, we expected that a DCC receptor with a mutation in the Fyn target tyrosine site, DCCY1418F, would behave like a dominant-negative receptor. Surprisingly, however, DCCY1418F fully rescues EW crossing defects (Fig. 5E, G; Table 1). DCCY1418F also generates a quantitatively similar phenotype to wild-type DCC when expressed in ap neurons (Fig. 4D). From these data, we conclude that the essential signaling motifs for Netrin-dependent commissural axon guidance are conserved between DCC and Fra, and that tyrosine phosphorylation of DCC at Y1418 is not required for its function in these neurons.

\section{Tyrosine phosphorylation of Fra is not required for CNS or motor axon guidance}

Based on these results, it appears that the role of Src family kinases in Drosophila axon guidance is distinct from that proposed in vertebrates. These results do, however, leave open the possibility that another nonreceptor tyrosine kinase may have a similar function in Drosophila. To determine whether tyrosine phosphorylation of Fra is involved in Netrin signaling, we tested whether a Fra receptor bearing mutations in all nine of the cytoplasmic tyrosines (Fra-9YF) can functionally replace endogenous fra in embryonic axons. We thus generated flies that express Fra-9YF under Gal4/UAS control. Using elav-Gal4 to drive expression in all neurons, Fra-9YF fully rescues fra commissural axon defects as visualized using the BP102 antibody to label CNS axons (Fig. 6A-D). Fra-9YF also rescues EW midline crossing defects in fra mutants to a similar extent as wild-type Fra (Fig. 5F; Table 1). These results suggest that tyrosine phosphorylation of Fra is not necessary for commissural axon guidance. fra mutants also have defects in motor axon guidance; in particular, the innervation of the Netrin-expressing ventral muscles 6/7 is frequently absent (Fig. 6G,H,K) (Mitchell et al., 1996), as visualized using the motor axon marker anti-FasII. Both wild-type Fra and Fra-9YF rescue these motor axon guidance defects when driven by elav-Gal4 (Fig. 6J,L), indicating that tyrosine phosphorylation of Fra
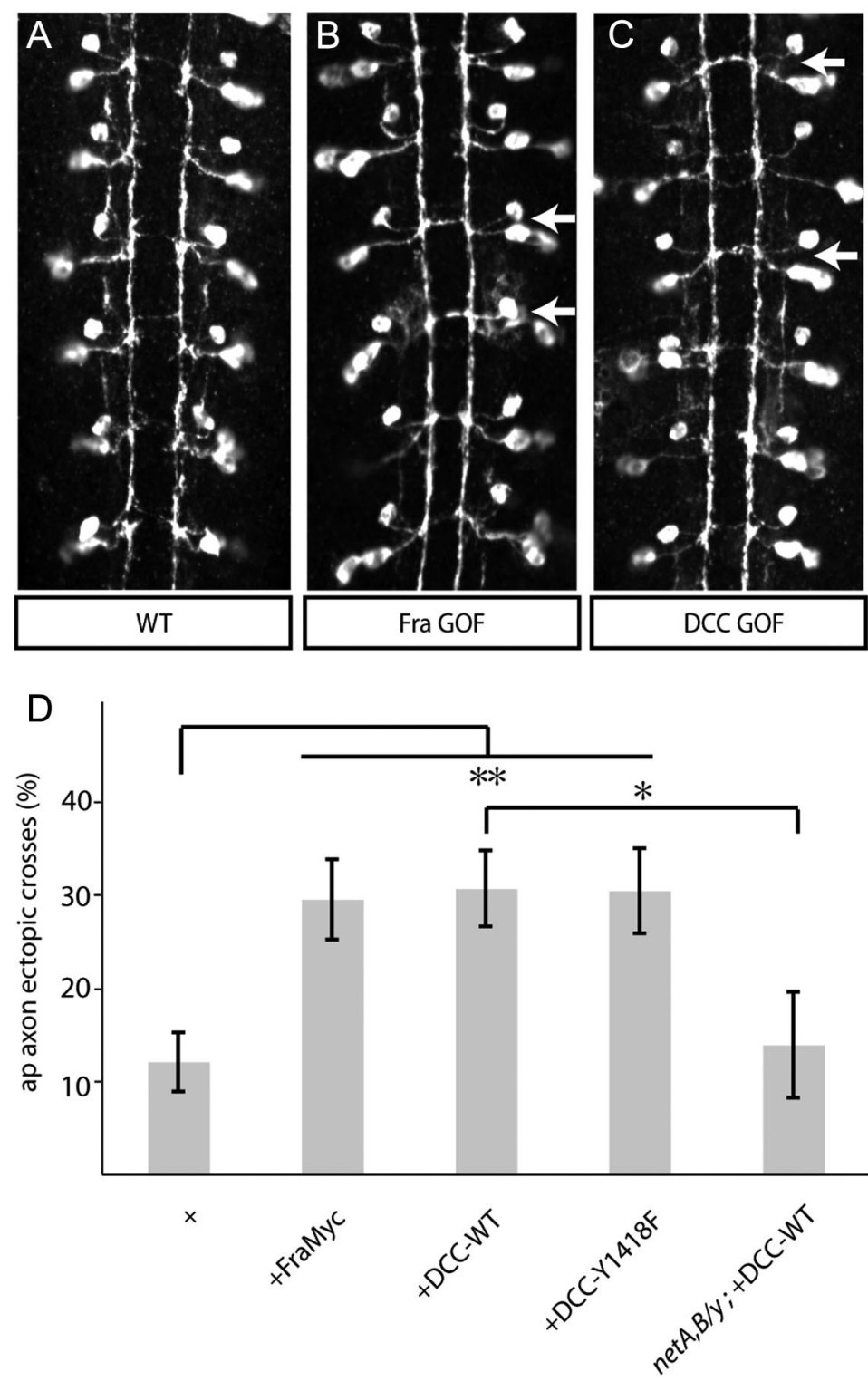

Figure 4. Vertebrate DCC can signal Netrin-dependent axon attraction in Drosophila. A-C, Stage 17 embryos, expressing TauMycGFP under control of $a p$-Gal4, are immunostained with anti-GFP to label the ipsilateral apterous axons. Six abdominal segments are shown. $\boldsymbol{A}$ Wild-type embryo. The ap axons remain ipsilateral. $\boldsymbol{B}$, Fra gain-of-function embryo. Ectopic crossing of ap axons occurs sporadically cation of ap ectopic crossing defects. DCC gain-of-function depends on Netrin (compare +DCC-WT and netA,B/y;+DCC-WT). Also, DCCY1418F gain-of-function is equivalent to DCC-WT in this assay. Error bars indicate SEM. ${ }^{*} p<0.05{ }^{* *} p<0.01$.

is dispensable for both commissural and motor axon guidance. Panneural expression of DCC does not, however, rescue motor guidance defects or longitudinal connective defects (Fig. 6E,L), and only mildly rescues the commissural guidance phenotype in fra mutants as assayed using BP102 (Fig. 6E), precluding the analysis of DCCY1418F in these contexts. Fra regulates the formation of longitudinal connectives through a nonautonomous function involving localization and presentation of Netrin (Hiramoto et al., 2000). These nonautonomous functions may not be conserved in DCC, which may explain the failure to rescue other fra-dependent embryonic phenotypes.

\section{Discussion}

We have found that in Drosophila, tyrosine phosphorylation of the attractive Netrin receptor Frazzled is not required for its embryonic axon guidance functions, and that Src tyrosine kinases 

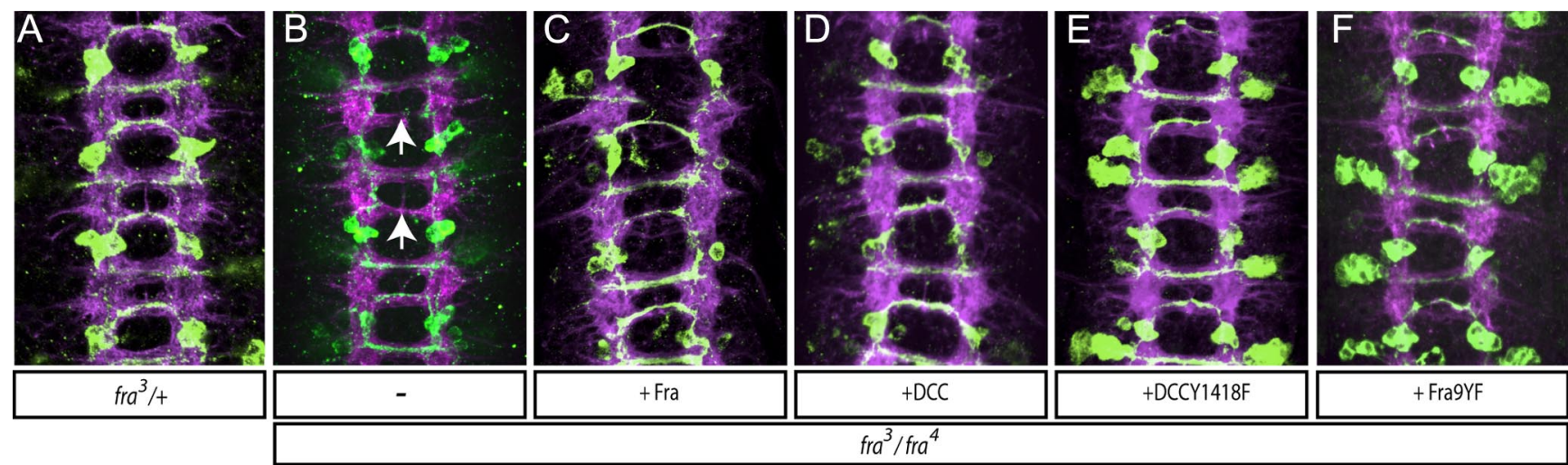

G
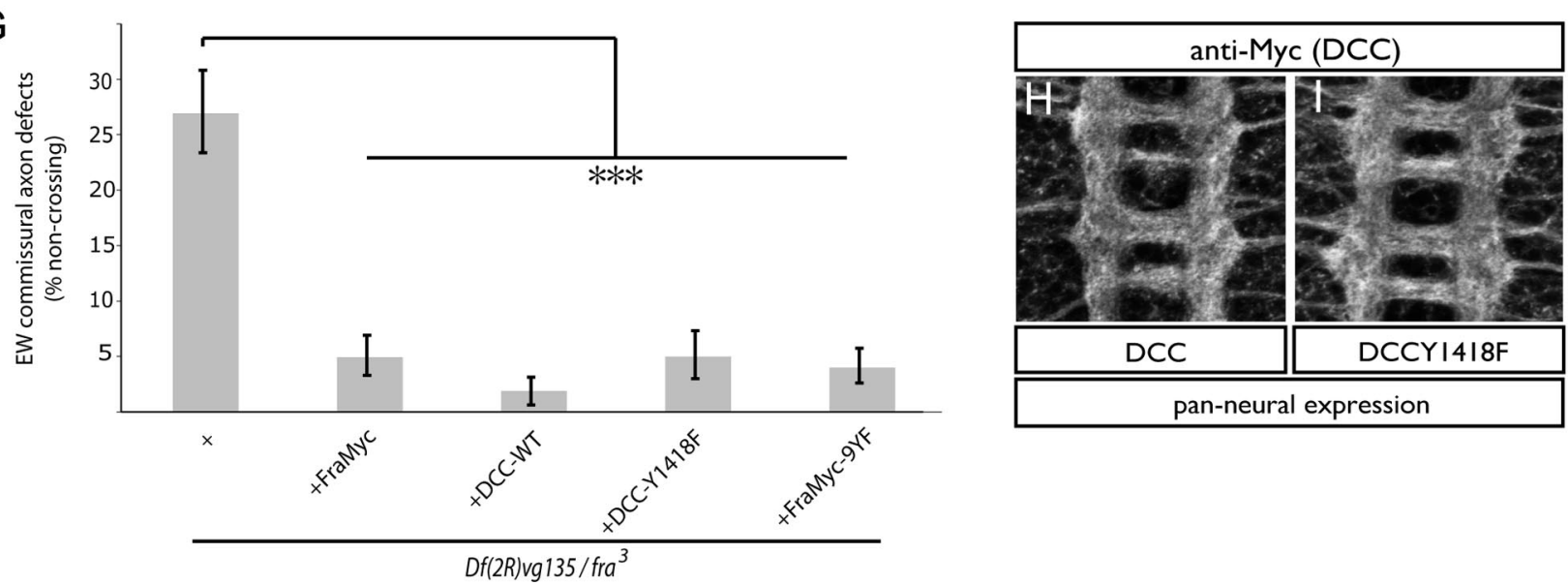

Figure 5. Tyrosine phosphorylation of DCC receptors is dispensable for midline axon guidance. $\boldsymbol{A}-\boldsymbol{F}$, Stage 15 control $(\boldsymbol{A})$ or fra mutant embryos (B-F) expressing TauMycGFP under control of eg-Gal4, along with various rescue transgenes indicated in boxes below. Embryos are immunostained with anti-GFP (green) to visualize EW axons and mAB BP102 (magenta) to visualize CNS axons. $\boldsymbol{A}$, Control embryo. All EW axons cross appropriately. $\boldsymbol{B}$, fra $^{3} / \mathrm{fra}^{4}$ mutant. Many EW axons fail to cross (arrows). $\boldsymbol{C}$, Fra-WT rescue. Most EW axons cross appropriately. $\boldsymbol{D}, \mathrm{DCC}$ rescue. Rescue of EW crossing is similar to that of Fra-WT. E, DCCY1418F rescue. The phenotype is indistinguishable from DCC-WT. $F$, Fra-9YF rescue. The phenotype is indistinguishable from Fra-WT. G, Quantification of EW crossing defects in fra ${ }^{3} \mathrm{Df}(2 \mathrm{R}) \mathrm{vg} 135$ mutants. Error bars indicate SEM. ${ }^{* * *} p<0.001$. For quantification of fra ${ }^{3} / \mathrm{fra}^{4}$ rescue, see Table 1 . $\boldsymbol{H}, \boldsymbol{I}$, Anti-Myc immunostaining to visualize DCC-Myc transgene expression levels, under control of pan-neural elav-Gal4. Transgenes are expressed at comparable levels.

antagonize Netrin-dependent axon attraction. These results contrast with the prevailing model of Src-dependent signal transduction through the DCC family of receptors (Li et al., 2004; Liu et al., 2004; Meriane et al., 2004; Ren et al., 2004; Round and Stein, 2007). There are three explanations that could potentially account for this discrepancy, which we will discuss here.

First, species-specific differences in signal transduction may have evolved between Drosophila and vertebrates. Supporting this possibility are the combined observations that DCC family members have multiple signaling outputs encoded by distinct cytoplasmic domains. For example, in Caenorhabditis elegans, the cytoplasmic P1 motif regulates branching and outgrowth through unc-34/enabled, and the P2 motif does so through a Racdependent pathway (Gitai et al., 2003). The P1 motif also regulates local mRNA translation in vertebrates (Tcherkezian et al., 2010), while the P3 motif interacts with phosphatidylinositol transfer protein alpha (Xie et al., 2005), Myosin X (Zhu et al., 2007), and FAK (Li et al., 2004; Ren et al., 2004; Lai Wing Sun et al., 2011). Only a subset of these signal transduction mechanisms may be required in a particular species. We do not favor this interpretation, although we cannot rule it out based on our observations. Because DCC can fully rescue the fra mutant phenotype in EW commissural neurons, we suggest that if there are Drosophila-specific signaling outputs downstream of Netrin in commissural neurons, these are retained in the vertebrate receptor. Also, with few exceptions, the diverse signaling outputs men- tioned above are all associated with highly conserved cytoplasmic domains, the P1, P2, and P3 motifs, though functional conservation between species has not been directly tested using these domains.

A second explanation for these contrasting results is that DCC's function in different cell types may reflect distinct cellbiological outputs, such that a particular signaling mechanism may only be necessary in a specific cell type or process. Support for this possibility comes from the observation that in response to Netrin, neurons expressing DCC family members can undergo multiple changes in cell morphology including polarization, axon outgrowth, axon turning, axon branching, and synaptic growth (Round and Stein, 2007; Lai Wing Sun et al., 2011). The particular changes in cell morphology that occur in response to Netrin depend on the cell type being evaluated, as well as the intracellular complement of signaling effectors and second messengers expressed at a given point in time. In some cases, intracellular effectors that have been implicated in mediating one of these diverse cell-biological outputs are not necessary for a different cellular response. For example, the tripartite motif protein encoded by the $C$. elegans gene madd-2 is required for axon branching and attractive guidance, but not for axon outgrowth induced by a constitutively active myristoylated Unc-40 receptor (Hao et al., 2010). While we cannot assay the intracellular environment in the cell types we tested, we provide evidence here that in at least two different neural cell types, embryonic commissural 

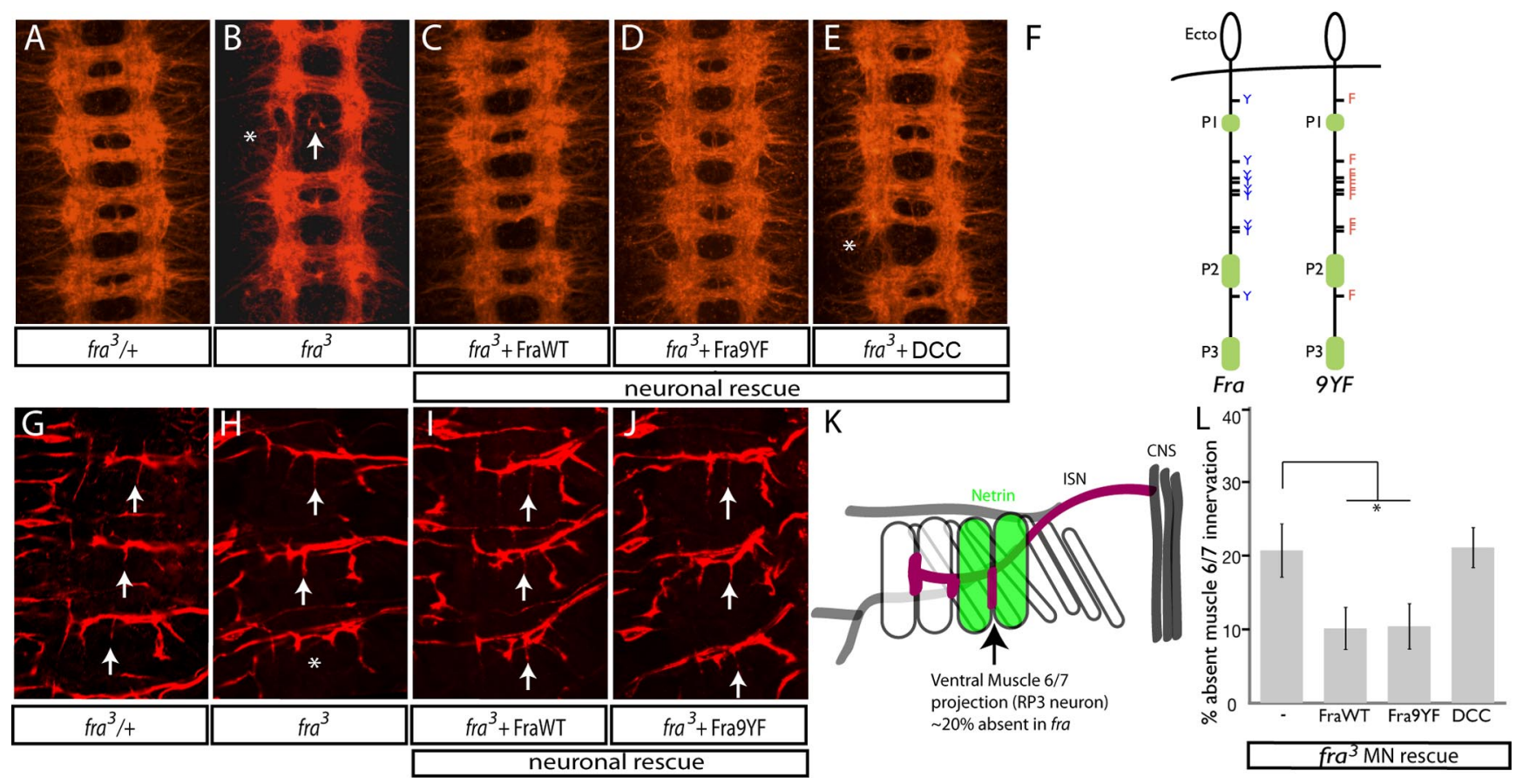

Figure 6. FragYF is equivalent to wild-type Fra in motor and CNS axon guidance. $\boldsymbol{A}-\boldsymbol{E}$, Stage 16 embryos immunostained with mAb BP102 to visualize CNS axons. Genotypes are boxed below panels. $\boldsymbol{A}$, Control embryo. $\boldsymbol{B}$, fra $^{3}$ mutant. Posterior commissures are thin or absent (arrow), and occasional breaks in longitudinal connectives occur (asterisk). $C-E$, Pan-neural rescue of fra ${ }^{3}$ mutants using elav-Gal4. C, Fra-WT rescues both commissural and longitudinal defects. D, Fra-9YF rescue similar to Fra-WT. E, DCC-WT shows marginal rescue of commissural thickness and fails to rescue longitudinal defects (asterisk). F, Diagram shows the location of nine cytoplasmic tyrosines (Y, blue) in wild-type Fra and the corresponding phenylalanine (F, red) residues in Fra-9YF. G-J, Stage 17 embryonic ventral motor field showing motor axons immunostained with anti-Fasll. Arrows indicate muscle 6/7 innervation. G, Control embryo. Most muscle 6/7 clefts show a Fasll-positive axon projection. $\boldsymbol{H}$, fra ${ }^{3}$ mutant. Two segments show proper targeting (arrows), but in one segment (asterisk), the 6/7 projection is absent. In this case, the RP3 axon has apparently stalled (right of the asterisk). $\boldsymbol{I}, \boldsymbol{J}$, Pan-neural rescue of fra ${ }^{3}$ using elav-Gal4. $\boldsymbol{I}$, Fra-WT rescue. Most 6/7 clefts are properly targeted. $\boldsymbol{J}$, Fra-9YF rescue. This phenotype is indistinguishable from Fra-WT. $\boldsymbol{K}$, Diagram depicting the location of Netrin-expressing muscle 6/7 (green), whose cleft is innervated by a Fasll-positive axon (magenta, arrow). L, Quantification of muscle 6/7 defects. Fra9YF rescues to a similar extent as Fra-WT, though DCC-WT does not. Error bars indicate SEM. ${ }^{*} p<0.05$.

interneurons and motor neurons, tyrosine phosphorylation of Fra is dispensable for Netrin-dependent guidance functions. Based on these observations, we conclude that if differences in intracellular milieu account for these distinct signaling requirements, then these must be shared between the two neural cell types we have assayed here.

An alternative to these possibilities, which are not mutually exclusive, is based on the observation that the substrate of adhesion dictates the intracellular signaling requirements and/or the directional growth of a migrating axon. Thus, navigating growth cones in vivo, which are likely to encounter distinct substrates than cultured cells, may respond differently to perturbations in a signaling cascade. This is perhaps best exemplified by the observation that in retinal ganglion cells expressing DCC, culturing on Laminin converts the normal attractive turning responses to repulsion (Höpker et al., 1999). The experiments performed by Meriane et al. (2004) and Li et al. (2004) using tyrosine mutant DCC receptors involved cultured cells, which were likely exposed to a different complement of adhesive substrates than the Drosophila neurons we have assayed here. However, experiments performed by Liu et al. (2004) showed that in spinal cord explant cultures, presumably exposed to the normal in vivo extracellular environment, inhibition of Fyn blocks turning responses to $\mathrm{Ne}$ trin. Thus, culture conditions are unlikely to fully explain the differing results here. Rescue experiments in vertebrates should allow help distinguish between these possibilities. For example, if DCC Y1418F can rescue guidance defects in commissural neurons in $d c c$ mutants, then this result would suggest that culture conditions are likely to explain these discrepancies. The alterna- tive outcome would suggest that either species or cell-typespecific differences in signaling are more likely to explain these results.

We have also shown that in addition to being dispensable for Netrin-dependent attraction in commissural neurons, Src family kinases actually antagonize midline axon crossing. Our observed dose-dependent genetic interactions are consistent with Src functioning to inhibit Fra, although our results suggest there must be Netrin-independent functions as well. So how, then, does Src antagonize midline crossing? We have tested multiple guidance pathways that use Src as a signaling effector that could, in principle, account for the genetic interactions we have observed here. However, this effect does not appear to be regulated by signaling downstream of integrins, the Drl/Ryk receptor, or Unc-5. Moreover, it is unlikely that the mechanism of Src-dependent inhibition of midline crossing occurs through direct phosphorylation of Fra, because we do not observe increased activity of the Fra9YF receptor when expressed in EW or apterous neurons.

Together, our observations suggest that Src likely functions in a novel parallel pathway to inhibit midline axon crossing. The partially penetrant phenotype of fra and Netrin mutants suggests that there must be a additional pathway promoting midline crossing in the Drosophila CNS. This Src-regulated pathway could potentially be either attractive or repulsive. Fra has been shown to regulate midline crossing through a canonical, Netrindependent pathway as well as a noncanonical Netrin-independent pathway (Yang et al., 2009). This Netrin-independent pathway occurs through transcriptional regulation of the Robo inhibitor, com- 
missureless. Our results in fra-null mutants are consistent with Src functioning in part to antagonize this pathway. However, the role of SFKs in commissural guidance is unlikely to exclusively involve repulsive Slit-Robo signaling because robo homozygous mutants do not suppress defects in the same genetic background that we have seen strong suppression using Src alleles. In vertebrates, the morphogen Sonic Hedgehog attracts commissural neurons to the floor plate through a SFK-dependent pathway (Yam et al., 2009). However, there is no evidence that Hedgehog directs commissural axons in Drosophila, and, given our results, Src kinases are unlikely to play a similar role as they antagonize midline crossing here. Two additional guidance cues regulate commissural axon guidance in the vertebrate CNS: ephrins and semaphorins (Evans and Bashaw, 2010). While there is evidence that SFKs play a role in ephrin and semaphorin signal transduction (Arvanitis and Davy, 2008; Zhou et al., 2008), data linking these cues to commissural guidance in Drosophila are lacking. Thus, the future identification of this novel pathway, which is likely regulated by Src activity, will yield a more complete understanding of mechanisms of midline axon crossing.

\section{References}

Arvanitis D, Davy A (2008) Eph/ephrin signaling: networks. Genes Dev 22: 416-429. CrossRef Medline

Benveniste RJ, Thor S, Thomas JB, Taghert PH (1998) Cell type-specific regulation of the Drosophila FMRF-NH2 neuropeptide gene by Apterous, a LIM homeodomain transcription factor. Development 125: 4757-4765. Medline

Brankatschk M, Dickson BJ (2006) Netrins guide Drosophila commissural axons at short range. Nat Neurosci 9:188-194. CrossRef Medline

Callahan CA, Muralidhar MG, Lundgren SE, Scully AL, Thomas JB (1995) Control of neuronal pathway selection by a Drosophila receptor proteintyrosine kinase family member. Nature 376:171-174. CrossRef Medline

Dittrich R, Bossing T, Gould AP, Technau GM, Urban J (1997) The differentiation of the serotonergic neurons in the Drosophila ventral nerve cord depends on the combined function of the zinc finger proteins Eagle and Huckebein. Development 124:2515-2525. Medline

Evans TA, Bashaw GJ (2010) Axon guidance at the midline: of mice and flies. Curr Opin Neurobiol 20:79-85. CrossRef Medline

Garbe DS, Bashaw GJ (2007) Independent functions of Slit-Robo repulsion and Netrin-Frazzled attraction regulate axon crossing at the midline in Drosophila. J Neurosci 27:3584-3592. CrossRef Medline

Garbe DS, O'Donnell M, Bashaw GJ (2007) Cytoplasmic domain requirements for Frazzled-mediated attractive axon turning at the Drosophila midline. Development 134:4325-4334. CrossRef Medline

Gitai Z, Yu TW, Lundquist EA, Tessier-Lavigne M, Bargmann CI (2003) The netrin receptor UNC-40/DCC stimulates axon attraction and outgrowth through enabled and, in parallel, Rac and UNC-115/AbLIM. Neuron 37:53-65. CrossRef Medline

Hao JC, Adler CE, Mebane L, Gertler FB, Bargmann CI, Tessier-Lavigne M (2010) The tripartite motif protein MADD-2 functions with the receptor UNC-40 (DCC) in netrin-mediated axon attraction and branching. Dev Cell 18:950-960. CrossRef Medline

Hin LY, Wang YG (2009) Working-correlation-structure identification in generalized estimating equations. Stat Med 28:642-658. CrossRef Medline

Hiramoto M, Hiromi Y, Giniger E, Hotta Y (2000) The Drosophila Netrin receptor Frazzled guides axons by controlling Netrin distribution. Nature 406:886-889. CrossRef Medline

Hoang B, Chiba A (1998) Genetic analysis on the role of integrin during axon guidance in Drosophila. J Neurosci 18:7847-7855. Medline

Höpker VH, Shewan D, Tessier-Lavigne M, Poo M, Holt C (1999) Growthcone attraction to netrin- 1 is converted to repulsion by laminin-1. Nature 401:69-73. CrossRef Medline

Itoh B, Hirose T, Takata N, Nishiwaki K, Koga M, Ohshima Y, Okada M (2005) SRC-1, a non-receptor type of protein tyrosine kinase, controls the direction of cell and growth cone migration in C. elegans. Development 132:5161-5172. CrossRef Medline

Kidd T, Brose K, Mitchell KJ, Fetter RD, Tessier-Lavigne M, Goodman CS, Tear G (1998) Roundabout controls axon crossing of the CNS midline and defines a novel subfamily of evolutionarily conserved guidance receptors. Cell 92:205-215. CrossRef Medline

Kolodziej PA, Timpe LC, Mitchell KJ, Fried SR, Goodman CS, Jan LY, Jan YN (1996) frazzled encodes a Drosophila member of the DCC immunoglobulin subfamily and is required for CNS and motor axon guidance. Cell 87:197-204. CrossRef Medline

Labrador JP, O'Keefe D, Yoshikawa S, McKinnon RD, Thomas JB, Bashaw GJ (2005) The homeobox transcription factor even-skipped regulates netrin-receptor expression to control dorsal motor-axon projections in Drosophila. Curr Biol 15:1413-1419. CrossRef Medline

Lai Wing Sun K, Correia JP, Kennedy TE (2011) Netrins: versatile extracellular cues with diverse functions. Development 138:2153-2169. CrossRef Medline

Legate KR, Wickström SA, Fässler R (2009) Genetic and cell biological analysis of integrin outside-in signaling. Genes Dev 23:397-418. CrossRef Medline

Li W, Lee J, Vikis HG, Lee SH, Liu G, Aurandt J, Shen TL, Fearon ER, Guan JL, Han M, Rao Y, Hong K, Guan KL (2004) Activation of FAK and Src are receptor-proximal events required for netrin signaling. Nat Neurosci 7:1213-1221. CrossRef Medline

Li X, Saint-Cyr-Proulx E, Aktories K, Lamarche-Vane N (2002) Racl and $\mathrm{Cdc} 42$ but not RhoA or Rho kinase activities are required for neurite outgrowth induced by the Netrin-1 receptor DCC (deleted in colorectal cancer) in N1E-115 neuroblastoma cells. J Biol Chem 277: 15207-15214. CrossRef Medline

Liu G, Beggs H, Jürgensen C, Park HT, Tang H, Gorski J, Jones KR, Reichardt LF, Wu J, Rao Y (2004) Netrin requires focal adhesion kinase and Src family kinases for axon outgrowth and attraction. Nat Neurosci 7:12221232. CrossRef Medline

Loureiro J, Peifer M (1998) Roles of Armadillo, a Drosophila catenin, during central nervous system development. Curr Biol 8:622-632. CrossRef Medline

Lu X, LiY (1999) Drosophila Src42A is a negative regulator of RTK signaling. Dev Biol 208:233-243. CrossRef Medline

Meriane M, Tcherkezian J, Webber CA, Danek EI, Triki I, McFarlane S, Bloch-Gallego E, Lamarche-Vane N (2004) Phosphorylation of DCC by Fyn mediates Netrin-1 signaling in growth cone guidance. J Cell Biol 167:687-698. CrossRef Medline

Mitchell KJ, Doyle JL, Serafini T, Kennedy TE, Tessier-Lavigne M, Goodman CS, Dickson BJ (1996) Genetic analysis of Netrin genes in Drosophila: Netrins guide CNS commissural axons and peripheral motor axons. Neuron 17:203-215. CrossRef Medline

O’Reilly AM, Ballew AC, Miyazawa B, Stocker H, Hafen E, Simon MA (2006) Csk differentially regulates Src64 during distinct morphological events in Drosophila germ cells. Development 133:2627-2638. CrossRef Medline

Pan W (2001) Akaike's information criterion in generalized estimate equations. Biometrics 57:120-125. CrossRef Medline

Ren XR, Ming GL, Xie Y, Hong Y, Sun DM, Zhao ZQ, Feng Z, Wang Q, Shim S, Chen ZF, Song HJ, Mei L, Xiong WC (2004) Focal adhesion kinase in netrin-1 signaling. Nat Neurosci 7:1204-1212. CrossRef Medline

Round J, Stein E (2007) Netrin signaling leading to directed growth cone steering. Curr Opin Neurobiol 17:15-21. CrossRef Medline

Seeger M, Tear G, Ferres-Marco D, Goodman CS (1993) Mutations affecting growth cone guidance in Drosophila: genes necessary for guidance toward or away from the midline. Neuron 10:409-426. CrossRef Medline

Shekarabi M, Kennedy TE (2002) The netrin-1 receptor DCC promotes filopodia formation and cell spreading by activating Cdc42 and Rac1. Mol Cell Neurosci 19:1-17. CrossRef Medline

Shekarabi M, Moore SW, Tritsch NX, Morris SJ, Bouchard JF, Kennedy TE (2005) Deleted in colorectal cancer binding netrin-1 mediates cell substrate adhesion and recruits Cdc42, Racl, Pak1, and N-WASP into an intracellular signaling complex that promotes growth cone expansion. J Neurosci 25:3132-3141. CrossRef Medline

Soriano P, Montgomery C, Geske R, Bradley A (1991) Targeted disruption of the c-src proto-oncogene leads to osteopetrosis in mice. Cell 64:693702. CrossRef Medline

Speicher S, García-Alonso L, Carmena A, Martín-Bermudo MD, de la Escalera de S, Jiménez F (1998) Neurotactin functions in concert with other identified CAMs in growth cone guidance in Drosophila. Neuron 20:221233. CrossRef Medline

Stein PL, Lee HM, Rich S, Soriano P (1992) pp59fyn mutant mice display 
differential signaling in thymocytes and peripheral T cells. Cell 70:741750. CrossRef Medline

Stein PL, Vogel H, Soriano P (1994) Combined deficiencies of Src, Fyn, and Yes tyrosine kinases in mutant mice. Genes Dev 8:1999-2007. CrossRef Medline

Stevens A, Jacobs JR (2002) Integrins regulate responsiveness to slit repellent signals. J Neurosci 22:4448-4455. Medline

Takahashi M, Takahashi F, Ui-Tei K, Kojima T, Saigo K (2005) Requirements of genetic interactions between Src42A, armadillo and shotgun, a gene encoding E-cadherin, for normal development in Drosophila. Development 132:2547-2559. CrossRef Medline

Tateno M, Nishida Y, Adachi-Yamada T (2000) Regulation of JNK by Src during Drosophila development. Science 287:324-327. CrossRef Medline

Tcherkezian J, Brittis PA, Thomas F, Roux PP, Flanagan JG (2010) Transmembrane receptor DCC associates with protein synthesis machinery and regulates translation. Cell 141:632-644. CrossRef Medline

Wouda RR, Bansraj MR, de Jong AW, Noordermeer JN, Fradkin LG (2008) Src family kinases are required for WNT5 signaling through the Derailed/ RYK receptor in the Drosophila embryonic central nervous system. Development 135:2277-2287. CrossRef Medline
Wright TR (1960) The phenogenetics of the embryonic mutant, lethal myospheroid, in Drosophila melanogaster. J Exp Zool 143:77-99. CrossRef Medline

Xie Y, Ding YQ, Hong Y, Feng Z, Navarre S, Xi CX, Zhu XJ, Wang CL, Ackerman SL, Kozlowski D, Mei L, Xiong WC (2005) Phosphatidylinositol transfer protein-alpha in netrin-1-induced PLC signalling and neurite outgrowth. Nat Cell Biol 7:1124-1132. CrossRef Medline

Yam PT, Langlois SD, Morin S, Charron F (2009) Sonic hedgehog guides axons through a noncanonical, Src-family-kinase-dependent signaling pathway. Neuron 62:349-362. CrossRef Medline

Yang L, Garbe DS, Bashaw GJ (2009) A frazzled/DCC-dependent transcriptional switch regulates midline axon guidance. Science 324: 944-947. CrossRef Medline

Zhou Y, Gunput RA, Pasterkamp RJ (2008) Semaphorin signaling: progress made and promises ahead. Trends Biochem Sci 33:161-170. CrossRef Medline

Zhu XJ, Wang CZ, Dai PG, Xie Y, Song NN, Liu Y, Du QS, Mei L, Ding YQ, Xiong WC (2007) Myosin X regulates netrin receptors and functions in axonal path-finding. Nat Cell Biol 9:184-192. CrossRef Medline 